\title{
Outcome of treatment of proximal tibial plateau fractures by minimally invasive percutaneous plating osteosynthesis technique
}

\section{Nageswara Rao Kancherla ${ }^{1}$, Khazi Syed Asif Hussain ${ }^{1}$, Mukthapuram Sreenath ${ }^{2}$, Vijaya Krishna Chilakamarri ${ }^{1}$}

\author{
${ }^{1}$ Department of Orthopedics, Nizams Institute of Medical Sciences, Hyderabad, Telangana, India \\ ${ }^{2}$ Department of Orthopedics, Kurnool Medical College, Kurnool, Andra Pradesh, India
}

Received: 09 August 2016

Accepted: 13 August 2016

\author{
*Correspondence: \\ Dr. Nageswara Rao Kancherla, \\ E-mail: nagortho@yahoo.co.in
}

Copyright: (C) the author(s), publisher and licensee Medip Academy. This is an open-access article distributed under the terms of the Creative Commons Attribution Non-Commercial License, which permits unrestricted non-commercial use, distribution, and reproduction in any medium, provided the original work is properly cited.

\begin{abstract}
Background: Fractures of the proximal tibia are accompanied by a wide range of severity which may include stable undisplaced fractures with minimal soft tissue injury to highly comminuted unstable fractures, and severe soft tissue involvement. With the better understanding of fracture healing biology and biomechanics of fracture fixation and healing, the trend of treatment is towards biological fixation, which can be accomplished by Minimally Invasive Percutaneous Plating Osteosynthesis (MIPPO) technique.

Methods: Demographic data of patients were recorded on admission and thorough history and clinical examination was done. The fractures were assessed for soft tissue injuries and followed by radiological assessment of fracture with schatzkers classification. The surgeries included anterolateral and anteromedial approaches for all patients with 'inverted hockey stick incision' and were treated with MIPPO. They were regularly followed up at 6-8 weeks interval till complete fracture union. A clinical and radiological evaluation was carried out using the modified Rasmussen clinical and radiological criteria.

Results: Out of the 20 patients treated, most of them were males and belonged to the age group of 20-40 years (75\%). Unilateral fractures were more common than bilateral fractures and were of the type 4 and type 5 of Schatzkers classification which was usually associated with high velocity RTA. One patient each had infection, varus deformity and knee joint stiffness. 10 fractures gave excellent result, 7 fractures healed with good results. Only 2 of the patients showed fair results and 1 had poor result.

Conclusions: All the fractures treated with MIPPO technique was found to be rapidly healing by secondary fracture union and hence achieving strong bone union across the fracture site due to inherent benefits of less tissue damage and minimal disturbance of fracture site biology.
\end{abstract}

Keywords: Proximal tibial plateau fractures, MIPPO, Outcome

\section{INTRODUCTION}

The proximal tibia is involved in body weight transmission through the knee joint and leg, it plays a vital role in the knee joint function and stability. ${ }^{1}$ Fractures of the proximal tibia are accompanied by a wide range of severity which may include stable undisplaced fractures with minimal soft tissue injury to highly comminuted unstable fractures, and severe soft tissue involvement and are generally classified into two broad catagories, high energy fractures and low energy fractures. ${ }^{2-4}$ The main reason for these fractures has been 
attributed to its subcutaneous location of the anteromedial surface of the tibia. The majority of tibial plateau fractures are secondary to high velocity road traffic accidents (RTA) and fall from height and were first described as car bumper fractures. ${ }^{5,6}$ These fractures resulted from direct axial compression, usually with a valgus (more common) or varus moment and indirect shear forces. ${ }^{7}$

Extra-articular fractures of the proximal tibia usually secondary to direct bending forces applied to the metadiaphyseal region of the upper leg. Older patients with osteopenic bone are more likely to sustain depression type fracture because their subchondral bone is less likely to resist axial directed load. ${ }^{8}$

Surgical treatment is gold standard for management of such fractures. This was done by conservative measures like cast bracing, traction, immobilization to surgical intervention for better results. Though these conventional methods achieved satisfactory results, it was still associated with shortcomings like large incisions, more blood loss and infection, hardware complications besides having some functional and alignment problems.

With the gradual changes in the treatment modalities of fracture proximal end tibia from conservative measures like cast bracing, traction, immobilization to surgical intervention for better results, there is a need for better fracture fixation technique in view of complications associated with conventional plating like radical exposure of fracture site and soft tissue injury. In addition there is osteoporosis and bone necrosis at bone plate and screw interface leading to infection, toggling of screw, loss of fixation, collapse, malunion and nonunion.

With the better understanding of fracture healing biology and biomechanics of fracture fixation and healing, the trend of treatment is towards biological fixation, which can be accomplished by MIPPO technique. Percutaneous fixation offers its best in isolated undisplaced fractures, split unicondylar fractures and in elderly osteoporotic bone. The advantages are decreased operative time, less blood loss, smaller incision, short hospital stay and early rehabilitation. $^{9}$

The aim of this study was to surgically treat the proximal tibia fracture with minimally invasive percutanoues plate osteosynthesis and to restore congruent articular surfaces of the tibial condyles, maintaining the mechanical axis and restoring ligamentous stability, thus to eventually achieve functional, stable, painless and good range of motion in the knee joint and prevent the development of osteoarthritis.

\section{METHODS}

This prospective study was conducted in Nizams institute of medical sciences study by the Department of Orthopedics and includes operations that were undertaken between January 2013 and September 2015. The total numbers of cases studied were 20 with the youngest 22 years and oldest 55 years old. Patients with proximal tibial fractures aged 20 years and above were included in the study. Demographic data of patients were recorded on admission and thorough history and clinical examination was done. The fractures were assessed for soft tissue injuries and followed by radiological assessment of fracture with Schatzker's classification.

Patients with Gustilo - Anderson Type-2 and type-3 compound proximal tibial fractures, children with proximal tibial fractures in whom the growth plate is intact, patients with pathological proximal tibial fractures other than osteoporosis, patients managed conservatively for being unfit for surgery and patients with proximal tibial fractures with neurovascular deficits were excluded from the study.

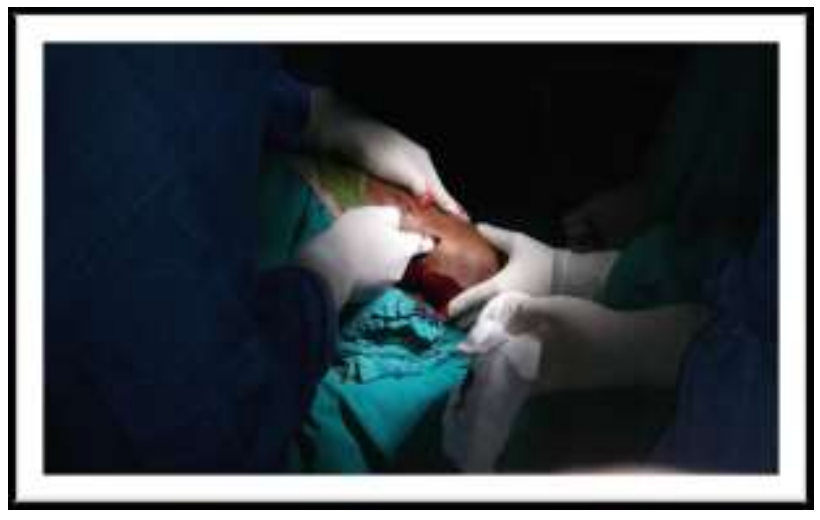

Figure 1: Proximal incision and insertion of plate in submuscular plane.

All the patients were operated with minimally invasive percutaneous plate osteosynthesis using buttress plate and locking compression plate. Prior to the surgery, once admitted, the fracture for all the patients was stabilized with slab immobilization and limb elevation given. Surgery delayed till favourable healing of soft tissue at operative site.

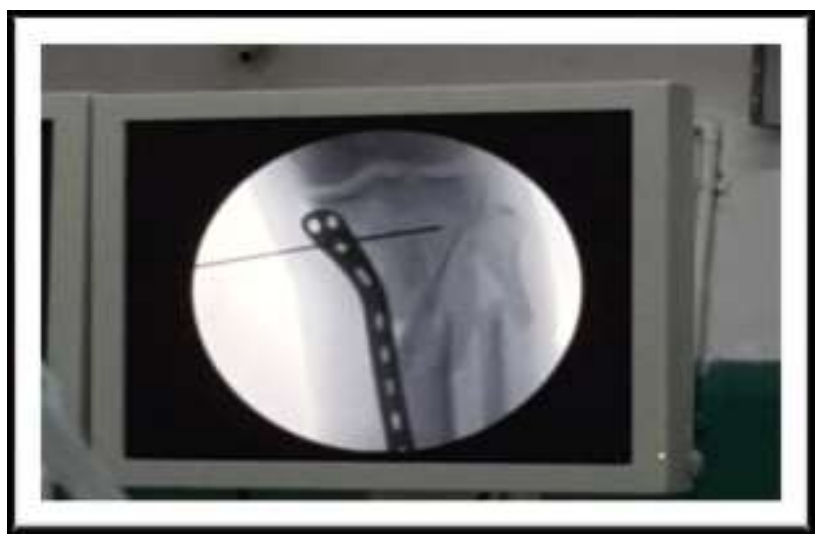

Figure 2: Proper placement of plate confirmed with C-Arm and maintained with $\mathrm{K}$-wire. 
All the patients were given prophylactic antibiotics prior to the surgery which was continued till the removal of the suture. They were stabilized hemodynamically and physical fitness for surgery was obtained. The length of plate, number of screws required and principle of fixation to be used was planned according the nature of the fracture.

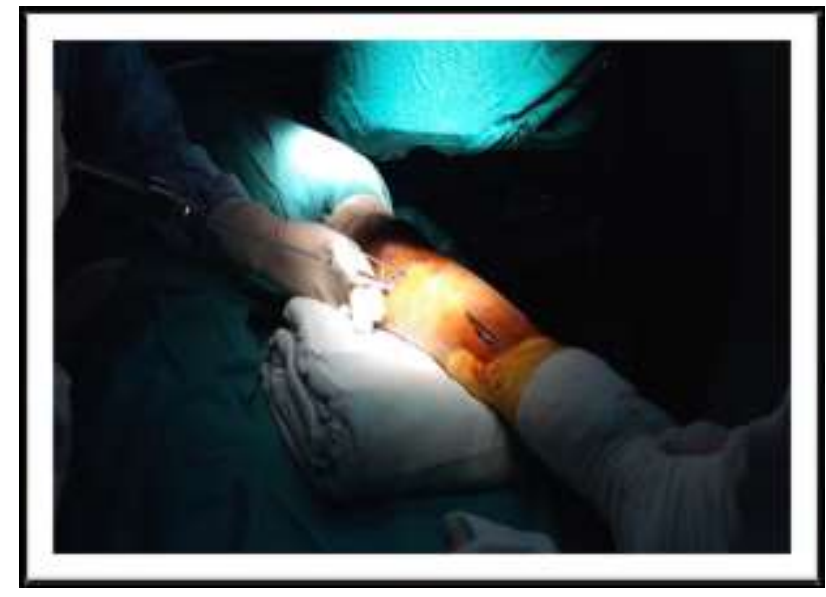

Figure 3: Fixed angle drill sleeve applied to the locking slot of plate to drill for insertion of locking screw.

The surgery included anterolateral and anteromedial approaches for all patients with 'inverted hockey stick incision'. The patients were placed supine on a fracture table to allow access to the image intensifier. Closed reduction of thefracture was done. The whole of operative limb was cleaned. A $2 \mathrm{~cm}$ incision was made proximal to the fracture site and a subcutaneous tunnel was created with the help of a periosteal elevator.

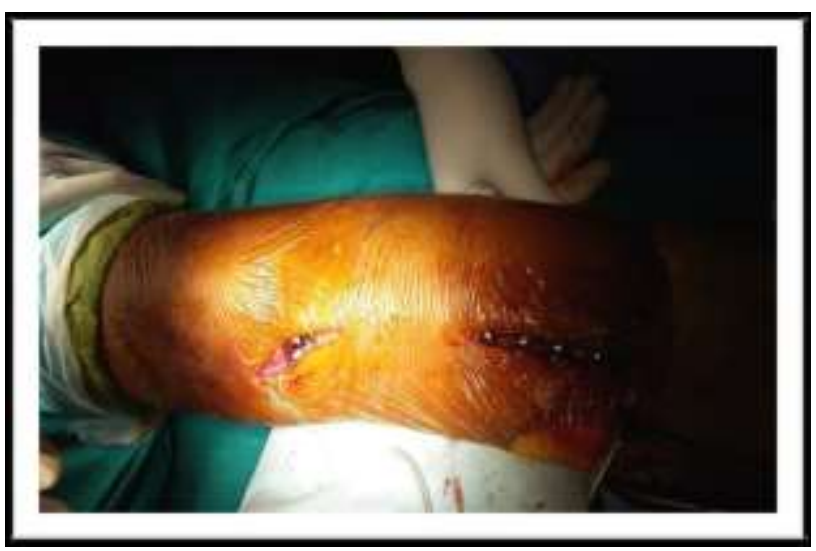

Figure 4: Final image after insertion of plate and screws.

The appropriate length of the plate ( $\mathrm{T}$ - buttress or a locking compression plate) was determined by placing a plate along the anterior aspect of the leg and adjusting it so that under fluoroscopy the proximal end of the plate is just below the joint line and the distal end extends at least three screw holes beyond the distal limit of the tibial fracture.

The plate was then slid subcutaneously across the fracture site to reach distal fragment. Another $2 \mathrm{~cm}$ incision was given distally where the plate ended. This plate was then contoured precisely to confirm to the condyle and proximal metaphyses and secured to the condyle with appropriate locking, cortical or cancellous screws of sufficient length (Figures 1-4).

The primary difference with the LCP is the method of locking head screw insertion. Here since the locking head of the screw has to get locked in the locking part of the combi hole, the direction of the drilling has to be perfect. Hence drilling for all locking head screws has to be after fixing drill sleeve to locking portion combi hole of plate. Non locking regular screws whenever used were inserted prior to insertion of the locking screws.

Based on the type of fracture and quality of fixation, the decision regarding continuation of external splint with Plaster of paris slab was made and patients were advised static quadriceps exercises. Partial weight bearing was delayed until 6 weeks and full weight bearing allowed after 12-16 weeks. All the patients were regularly followed up at 6-8 weeks interval till complete fracture union. The moment of complete healing was defined as radiologically complete bone regeneration at fracture site. Any loss of reduction or any sign of complication was carefully noted.

A clinical and radiological evaluation was carried out using the modified Rasmussen clinical and radiological criteria $^{10}$.

\section{RESULTS}

A total of 20 patients with proximal tibial fractures who were treated with MIPPO technique were studied. Most of the patients belonged to the age group of 20-40 years (75\%), which was the highly active and mobile age, thereby being prone to Road traffic accidents (Table 1). Out of the total 20 patietns, only $2(10 \%)$ of them were females and $18(90 \%)$ were males.

\section{Table 1: Age distribution.}

\begin{tabular}{|lll|}
\hline Age group (In years) & $\begin{array}{l}\text { Number of } \\
\text { patients }\end{array}$ & Percentage \\
\hline $20-30$ & 9 & $45 \%$ \\
\hline $31-40$ & 6 & $30 \%$ \\
\hline $41-50$ & 3 & $15 \%$ \\
\hline $51-60$ & 2 & $10 \%$ \\
\hline$>60$ & 0 & 0 \\
\hline
\end{tabular}

Unilateral fractures were more common than bilateral, and the right side showed a slight predominance over the 
left, although this was not found to be significantly relevant (Figure 5).

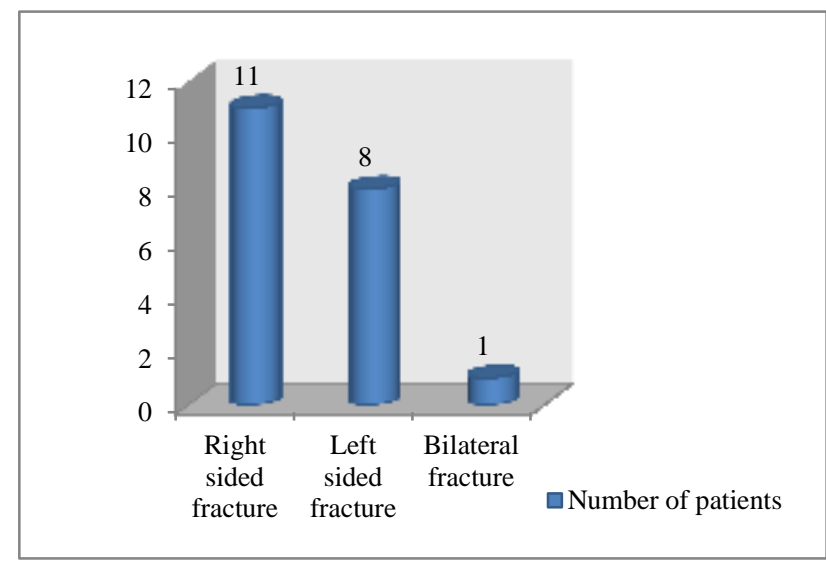

Figure 5: Side of fracture.

Most of the fractures were of the type 4 and type 5 of Schatzkers classifications which were usually associated with high velocity RTA (Figure 6).

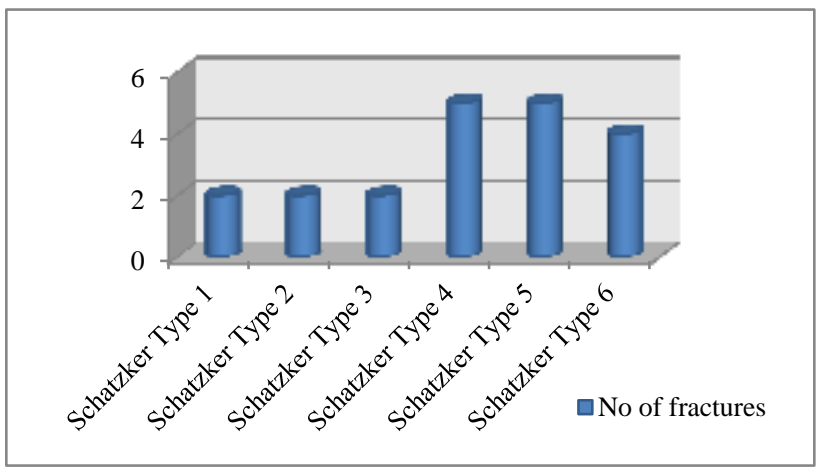

Figure 6: Type of Fracture (Schatzkers classification).

Out of the complications observed, one patient had infection which was immediate postoperative infection in a patient with compound fracture which was treated with thorough debridement and antibiotics. One patient had knee joint stiffness which was associated with compound comminuted supracondylar fracture femur with intercondylar extension. One patient had varus deformity due to collapse of medial condyle postoperatively (Table 2).

Table 2: Complications.

\begin{tabular}{|lll|}
\hline Complications & $\begin{array}{l}\text { Number of } \\
\text { patients }\end{array}$ & Percentage \\
\hline Infection & 1 & $5 \%$ \\
\hline Knee Joint Stiffness & 1 & $5 \%$ \\
\hline Varus Deformity & 1 & $5 \%$ \\
\hline
\end{tabular}

Out of 20 fractures treated, 10 fractures gave excellent result, 7 fractures healed with good results. Only 2 of the patients showed fair results and 1 had poor result (Table $3)$.

Table 3: Clinical and radiological outcomes based on modified Rasmussen criteria.

\begin{tabular}{|lll|}
\hline Clinical results & $\begin{array}{l}\text { Number of } \\
\text { fractures }\end{array}$ & Percentage \\
\hline Excellent & 10 & 50 \\
\hline Good & 7 & 35 \\
\hline Fair & 2 & 10 \\
\hline Poor & 1 & 5 \\
\hline Total & $\mathbf{2 0}$ & $\mathbf{1 0 0}$ \\
\hline
\end{tabular}

\section{DISCUSSION}

The incidence of proximal tibial fractures has not only increased with increase in RTA but also the complexity of fracture has changed due to high velocity direct impact causing more comminution at fracture site. Any fracture around the weight bearing joint like knee joint is of paramount importance as these would result in significant morbidity and compromised quality of life. Moreover, the management of high energy proximal tibia fractures is a challenging task for the surgeon, as they are often associated with a number of complications. ${ }^{3,11-13}$

Of late with the better understanding of peculiarities in proximal tibial fracture, fracture healing, and complications associated with them, there has been research in better tissue friendly approaches (MIPPO) and development of better technically mature implant systems (LCP) for fracture fixation, which are showing promising results by early restoration of strength at fracture site and function of knee joint.

MIPPO enables indirect fracture reduction and percutaneous sub muscular implant placement ${ }^{14}$. Favourable outcome is not due to MIPPO but due to less extensive dissection of soft-tissue envelope and devitalisation of fracture fragments.

The patients with fracture in our study occurred between the age of 20 to 60 years with maximum incidence involving the productive age group of 20-50 years (90\%). This was in accordance with a study by P.A Cole et al in 2004 who also found the majority of patients in productive age with an average of 45 years, and with the study of Ricci and Stannard with average of 53 years and 38 years respectively. ${ }^{15-17}$ In another Indian study by Sharma et al, similar results were found where RTA was the most common cause of fractures. ${ }^{18}$ This is due to the high probability of injuries occurring in this age group due to RTA.

In our series majority of the patients were males $90 \%$, which can be attributed to our Indian setup where the female population largely work indoor and do not travel much. 
In our study the commonest mode of injury was road traffic accident (95\%) the other being assault (5\%). There was not much difference in the laterality of the fracture. The right tibia was affected in $55 \%$, left tibia in $40 \%$ of cases and bilateral in $5 \%$ of cases.

In this study, out of the 20 fractures, most of them fell into schatzkers type 4 and type 5 classification of proximal tibial fractures. In the study by Sharma et al, type 5 and 6 were more common as was seen in a another study by Marsh et $\mathrm{al}^{19}$, while in a study by Raza et al, type 3 and type 2 were found to be the predominant ones. $^{20}$

The average time for union of fractures was 19 weeks in our series ranging from 16 to 24 weeks. An average of $121^{\circ}$ knee joint range of motion was achieved. Soft tissue damage, intraarticular fracture, severity of fracture and physiotherapy determined knee range of motion. Both Cole et al and Egol et al reported similar range of movement results when using locked plate for these fractures (range 0 to $122^{\circ}$ and 0 to $109^{\circ}$ respectively). ${ }^{15,21}$

Amongst the complications observed, 1 patient (5\%) developed infection within 2 weeks postoperatively, which was comparable to the studies conducted by Egol et $\mathrm{al}^{21}$ who reported no infection, Stannard et $\mathrm{al}^{17}$ reported $5.9 \%$ rate of infection and Cole et al ${ }^{15}$ with $4 \%$ rate of infection. The mal-alignment rate was $5 \%$ in our study, as compared to $2.6 \%$ in a study by Cole et al and $22 \%$ in the study by Phistikul et $\mathrm{al}^{22}$.

We had excellent clinical and radiological outcome in $50 \%$ of the cases and in $35 \%$ of the cases, it was good. Only in $1(5 \%)$ of the patients the result was poor. Reddy et al reported an excellent result in $86.7 \%$ of the cases and $13.3 \%$ had good results, while in a study by Rohra et al, $85.29 \%$ of the patients had excellent and $14.71 \%$ had good results. ${ }^{23}$ Simialr results were observed by Yu et al, Prasad et al, Zhang et al, Oh et al. ${ }^{25-28}$

\section{CONCLUSION}

There is an increase in the complexity of proximal tibial fractures with increasing road traffic accident. As most of the patients sustained these fractures belong to physically highly active and productive age group, they need optimal treatment to get back to their previous work capacity and avoid long term complications like osteoarthiritis. We treated all fractures in our study with MIPPO technique and found rapid healing by secondary fracture union and hence achieving strong bone union across the fracture site due to inherent benefits of less tissue damage and minimal disturbance of fracture site biology.

Funding: No funding sources Conflict of interest: None declared

Ethical approval: The study was approved by the institutional ethics committee

\section{REFERENCES}

1. Egol KA, Koval KJ. In: Fracture of proximal tibia: chapter 50, Rockwood and Green's "Fracture in Adults", Vol. 2, $6^{\text {th }}$ edition, Lippincott Williams and Wilkins. 1999.

2. Shepherd L, Abdollahi K, Lee J, Vangsness CT Jr. The prevalence of soft tissue injuries in nonoperative tibial plateau fractures as determined by magnetic resonance imaging. J Orthop Trauma. 2002;16(9):628-31.

3. Lansinger O, Bergman B, Korner L, Andersson GB. Tibial condylar fractures. A twentyyear follow-up. J Bone Joint Surg Am. 1986;68:13-9.

4. Pape HC, Giannoudis P, Krettek C: The timing of fi;racture treatment in polytrauma patients: Relevance of damage control orthopedic surgery. Am J Surg. 2002;183(6):622-9.

5. Schulak DJ, Gunn DR. Fracture of the tibial plateaus. Clin Orthop. 1975;109:166-77.

6. Cotton FB. Fender fracture of the tibia at the knee. N Engl J Med. 1929;201:989.

7. Koval KJ, Hulfut DL. Tibial plateau fracture: evaluation and treatment. J Am Acad Orthop Surg. 1995;3(2):86-94.

8. Biyani A, Reddy NS, Chaudhary et al. The results of surgical management of displaced tibial plateau fracture in the elderly. Injury. 1995;26(5):291-7.

9. Sirkin MS, Bono CM, Reilly MC and Behrens FF. Percutaneous methods of tibial plateau fixation. Clin Orthop 2000;375:60-8.

10. Rasmussen PS. Tibial condylar fractures. Impairment of knee joint stability as an indication for surgical treatment. J Bone Joint Surg Am. 1973;55:1331-50.

11. Young MJ, Barrack RL. Complications of internal fixation of tibial plateau fractures. Orthop Rev 1994;23:149-54.

12. SchatzkerJ, McBroom R, Bruce D:The tibial plateau fracture: The Toronto experience 1968-1975. Clin Orthop. 1979;(138):94-104.

13. Papagelopoulos PJ, Partsinevelos AA, Themistocleous GS, et al. Complications after tibia plateau fracture surgery. Injury. 2006;37:475-484. doi: 10.1016/j.injury.2005.06.035.

14. Cole PA, Zlowodzki M, Kregor PJ. Less invasive stabilization system (LISS) for fractures of the proximal tibia: indications, surgical technique and preliminary results of the UMC Clinical Trial. Injury. 2003;34(Suppl 1):A16-29.

15. Cole PA, Zlowodzki M, Kergor J. Treatment of proximal tibia fracture using the Less Invasive Stabilization System. Surgical experience and early clinical results in 77 fractures. J Orthop. 2004;18:528-35.

16. Ricci WM, Rudzki JR, Borrelli J Jr. Treatment of complex proximal tibial fracture with the less invasive skeletal stabilization system. J Orthop Trauma. 2004;18:521-7. 
17. Stannard JP, Wilson TC, Volgas DA, Alonso JE. Fracture stabilization of proximal tibial fracture with the proximal LISS: early experience in Birmingham, Alabama (USA). Injury. 2003;34:A30-5.

18. Rakesh Sharma, Rajesh Kapila, Brahm Preet Singh, Yadwinder Singh Sohal. Traditional buttress plating $\mathrm{v} / \mathrm{s}$ MIPO in management of proximal tibial fractures - A clinical study. $\mathrm{Pb}$ Journal of Orthopaedics. 2013;14(1):11-6

19. Marsh JL, Smith ST, Do TT. External fixation and limited internal fixation for complex fractures of the tibial plateau. J Bone Joint Surg Am. 1995;77A:661-73.

20. Raza H, Hashmi P, Abbas K, Hafeez K. Minimally invasive plate osteosynthesis for tibial plateau fractures. Journal of Orthopaedic Surgery 2012;20(1):42-7.

21. Egol KA, Su E, Tejwani NC, Sims SH, Kummer FJ, Koval KJ. Treamtent of complex tibial plateau fractures using the less invasive stabilization system plate. J trauma. 2004;57:340-6.

22. Phisitkul P, McKinley TO, Nepola JV, Marsh JL. Complications of locking plate fixation in complex proximal tibia injuries. J Orthop Trauma; 2007;21,83-91.

23. Reddy JPK, Nazeer BS, Arun HS, Kumar NM. Study of surgical management of proximal tibial fractures using locking compression plate. IJBAR. 2016;07(03):123-7.
24. Rohra N, Suri HS, Gangrade K. Outcome of Schatzker Type V and VI Tibial Plateau Fracture Treatment with Dual Plates. Journal of Clinical and Diagnostic Research. 2016;10(5):RC05-10.

25. Yu Z, Zheng L, Zhang Y, Li J, Ma B. Functional and radiological evaluations of high energy tibial plateau fractures treated with double-buttress plate fixation. Eur J Med Res. 2009;14(5):200-05.

26. Prasad GT, Kumar TS, Kumar RK, Murthy GK, Sundaram N. Functional outcome of Schatzker type $\mathrm{V}$ and VI tibial plateau fractures treated with dual plates. Indian J Orthop. 2013;47(2):188-94.

27. Zhang Y, Fan D, Ma B, Sun S. Treatment of complicated tibial plateau fractures with dual plating via a 2-incision technique. Orthopedics. 2012;35(3):e359-64.

28. Oh CW, Oh JK, Kyung HS, Jeon IH, Park BC, Min WK, et al. Double plating of unsta-ble proximal tibial fractures using minimally invasive percutaneous osteosynthesis tech-nique. Acta Orthop. 2006;77(3):524-30.

Cite this article as: Kancherla NR, Hussain KSA, Sreenath M, Chilakamarri VK. Outcome of treatment of proximal tibial plateau fractures by minimally invasive percutaneous plating osteosynthesis technique. Int J Res Orthop 2016;2:132-7. 